\title{
CURIE: a low power X-band, low atmospheric Boundary Layer Doppler radar
}

\author{
Hassan Al-SakKa ${ }^{1 *}$, Alain Weill ${ }^{1}$, Christophe Le GaC ${ }^{1}$, Richard Ney $^{1}$, Laurent \\ CHARDENAL ${ }^{1}$, JEAN PAUl VINSON ${ }^{1}$, LAURENT BARTHÈs $^{1}$ and ERIC DUPONT ${ }^{2}$ \\ ${ }^{1}$ Laboratoire Atmosphères, Milieux, Observations Spatiales, LATMOS/IPSL, Vélizy, France \\ ${ }^{2}$ EDF-R\&D - CEREA, Chatou cedex, France
}

(Manuscript received September 12, 2008; in revised form December 12, 2008; accepted February 23, 2009)

\begin{abstract}
A new X-band Doppler miniradar, the CURIE radar (Canopy Urban Research on Interactions and Exchanges), mainly adapted to low Atmospheric Boundary Layer ABL sounding has been developed at LATMOS (Laboratoire Atmosphères, Milieux, Observations Spatiales) formerly CETP (Centre d'étude des Environnements Terrestre et Planétaires). After a brief description of the measurement conditions in a turbulent atmosphere, the main characteristics of the new sensor are presented. As an example, we compare CURIE vertical velocity f uctuations with UHF observations to show the vertical velocity measurement validity. As a prospective area of application in clear air, we focus on a f rst observation of vertical velocity variance which is supposed to be related to entrainment across the inversion layer. As our objective is to study low boundary layers during different atmospheric conditions and since the radar works in the presence of precipitation (as all X-band radar do), we also show vertical rain soundings in the lower part of the ABL and illustrate our f ndings with results demonstrating comparable ref ectivity and precipitation rates as estimated with a disdrometer and with a rain gauge.

\section{Zusammenfassung}

Ein neues X-Band-Dopppler-Miniradar, das sog. CURIE-Radar (Canopy Urban Research on Interactions and Exchanges) wurde am LATMOS (Laboratoire Atmospheres, Milieux, Observations Spatiales), früher CETP (Centre d'étude des Environnements Terrestre et Planétaires) entwickelt. Es ist hauptsächlich für die Anwendung in der unteren atmosphärischen Grenzschicht vorgesehen. Nach kurzer Beschreibung der Messbedingungen in der turbulenten Atmosphäre wurden die wesentlichen Charakteristika des neuen Systems päsentiert. Es wurden als Beispiel mit CURIE gemessene Vertikalgeschwindigkeitsf uktuationen mit UHFBeobachtungen verglichen, um die Qualität der Methode aufzuzeigen. Unter clear-air-Bedingungen konzentrieren wir uns auf die Beobachtung der Varianz der Vertikalgeschwindigkeit, von der angenommen wird, dass sie ein Ausdruck für den Entrainment-Prozess in der Inversionsschicht ist. Bei der Untersuchung der unteren atmosphärischen Grenzschicht während unterschiedlicher atmosphärischer Bedingungen, konnten wir auch vertikale Regenechos im unteren Teil der ABL registrieren, da das CURIE (wie alle Radars) auch bei Niederschlägen arbeitet. Es wurden unseren Ergebnissen vergleichbare Ref exions- und Niederschlagsraten, die mit Disdrometern und Regenmessern erhalten wurden, gegenübergestellt.
\end{abstract}

\section{Introduction}

Knowledge of air dynamics in the lower atmosphere is necessary for several kinds of investigations especially with the requirement for a $\mathrm{f}$ ne spatial vertical resolution close to $20 \mathrm{~m}$ in the frst $500 \mathrm{~m}$ of the ABL and with a f rst level of observation as low as possible to have at least a measurement in the surface layer. For example, pollution studies have to be connected to the UBL (Urban Boundary Layer) and take into account the exchange processes at the top of the city itself which concerns particularly the city canopy. This zone can in principle be covered by Sodar and Lidar measurements but:

\footnotetext{
${ }^{*}$ Corresponding author: Hassan Al-Sakka, Laboratoire Atmosphères, Milieux, Observations Spatiales, LATMOS/IPSL, 10-12 Avenue de L'Europe, 78140 Vélizy, France e-mail: hassan.al-sakka@latmos.ipsl.fr
}

- Sodar is not very eff cient in extremely noisy environments present in some urban areas such as the edges of highways. Furthermore, Sodar noise itself does not seem to be socially accepted by city inhabitants. However as shown by LiTTLE (1972), acoustic ref ectivity (for Sodar) is larger than electromagnetic ref ectivity (for radar) in the ABL, but this superiority does not outweigh the presence of large acoustic noise;

- Lidar may be unable to work correctly in very low atmospheric layers in case of too many particles and intense low level fogs. Above typically $300 \mathrm{~m}$ height, ST Radar (UHF, VHF) and Lidar are indisputably privileged instruments.

These considerations account for an interest to develop an instrument equivalent to Sodar but not sensitive to ambient acoustic noise and without any acoustic noise generation. For that purpose, we have developed a new 
Table 1: Description of scientif c prototype of CURIE

\begin{tabular}{ll}
\hline Characteristic & Value \\
\hline Power & $70 \mathrm{~W}$ \\
Frequency & $9.42 \mathrm{Ghz}$ \\
Pulse width: - Biphase mode & $150 \mathrm{~ns}$ \\
- Coded mode & Codes length $4,8,16$ \\
(Spano code) & binary elements \\
Repetition period & $0.6 \mu \mathrm{s}$ to $4.8 \mu \mathrm{s}$ \\
Spatial resolution & $22.5 \mathrm{~m}$ \\
Antenna Gain & $40 \mathrm{dBi}$ \\
Aperture & $1.9^{\circ}$ \\
\hline
\end{tabular}

X-band Radar CURIE for Urban Canopy Research and study of Interactions and Exchanges.

$\mathrm{X}$-band was chosen because small antennas can be used, which is convenient in an urban conf guration. The possibility to develop a low power, less expensive radar using a solid state transmitter system was another reason. VHF and UHF radar working in clear air are based in principle on Bragg scattering in the inertial subrange of small scale turbulence if turbulence is rising in the atmospheric boundary layer, see for example TATARSKII (1961) and OTTERSTEN (1969). However, an important question was the feasibility of clear air Bragg scattering for centimeter wavelengths in the inertial subrange, since centimeter waves are close to the dissipation range. Several observations (for acoustic waves) using for example $6 \mathrm{kHz}$ up to $20 \mathrm{kHz}$ corresponding (for Bragg scattering) to a turbulence wavelength $\lambda_{\text {Turb }}$ between $0.8 \mathrm{~cm}$ and $2.5 \mathrm{~cm}$, have shown convincing turbulent responses since high frequency minisodars have been used for turbulence studies, see for example COULTER and MARTIN (1986) and WeILl et al. (1986).

For centimeter electromagnetic waves, Bragg sounding must be also possible, since for passive scalar like temperature, humidity and also radio index fuctuations, the lower scale limit of the inertial subrange (the Kolmogorov scale) in the low boundary layer, is close to one mm, see HILL (1989) and GIBSON (1991). The Kolmogorov length scale is indeed $\left(\nu^{3} / \varepsilon\right)^{0.25}$ where $\nu$ is the kinematic viscosity and $\varepsilon$ the turbulent dissipation rate, see Kallistratova (1959) and Monin (1962). As an example, with an air kinematic viscosity close to $1.510^{-5} \mathrm{~m}^{2} \mathrm{~s}^{-1}$ at $20^{\circ} \mathrm{C}$ and a turbulent dissipation rate between $5.010^{-5}$ and $6.2510^{-3} \mathrm{~m}^{2} \mathrm{~s}^{-3}$ at $50 \mathrm{~m}$ corresponding to typical friction velocities in the low boundary layer between $0.1 \mathrm{~m} \mathrm{~s}^{-1}$ and $0.5 \mathrm{~m} \mathrm{~s}^{-1}$, one obtains a Kolmogorov scale between $0.9 \mathrm{~mm}$ and $2.9 \mathrm{~mm}$.

CURIE observations in clear air have shown that this assumption was relevant, but it does not take into account the possible cases of low turbulence levels in which the Kolmogorov dissipation scale can increase up to centimeters. During these cases the CURIE signal can be drastically reduced by viscous damping, near the dissipation range of turbulence following GOSSARD et al. (1984).
Another important point is the minimum of turbulence to be detected. To be very sensitive to turbulence in the ABL, CURIE ref ectivity, in term of $C_{n}^{2}$, the refractive index structure parameter, should be at least of $10^{-16}$ $\mathrm{m}^{-2 / 3}$, see NEFF and COULTER (1986).

The use of radar for precipitation analysis is of course not innovative and Doppler radar at vertical incidence and high power radar have already been used since more than thirty years, see ATLAS et al. (1973). Vertically pointing, low power, very small radar specif cally adapted for rain observations as K-band Micro Rain Radar (MMR), LÖFFLER-MANG et al. (1999) and PETERS et al. (2002) are now routinely utilized. It has to be also noted that low power, solid state X-band radar has been also used in the recent past in the USA for different atmospheric uses, as done by BLUESTEIN and UNRUH (1989) to compute wind spectra in tornadoes and for studying other phenomena and that an X-band radar network CASA (Collaborative Adaptive Sensing of the Atmosphere) is also used in central Oklahoma for monitoring and studying tornadoes and severe thunderstorms. CURIE was designed at $\mathrm{f}$ rst for clear air studies, but its ability to complement clear air observations with precipitation observations warrants to be analyzed. It is indeed usual in boundary layer studies to look at clear air conditions, but the boundary layer just before, during and after rain remains an important topic for the physics of atmospheric boundary layer.

In this paper, after the CURIE radar and data processing description in section 2, we present several observations of CURIE in section 3. The subsection 3.1 is devoted to low clear air ABL and subsection 3.2 concerns a few results during precipitation. Some conclusions and perspectives of CURIE use are f nally presented.

\section{Radar description and data processing}

Figure 1 shows a picture of CURIE on the top of the measurement shelter at SIRTA (Site Instrumental de Recherche par Télédétection Atmosphérique).

CURIE is a pulse coded X-band Radar. The description of this radar is summed up in Table 1. An offset antenna is used to minimize the effects of secondary beams and ground clutter (f xed echoes). The orientation of this antenna is piloted by an azimuth and elevation positioning system. The received signal is amplif ed, down-converted, fltered and then sampled at the intermediate frequency of $60 \mathrm{MHz}$.

Signal generation (pulse modulation), digital reception, coherent integration and decoding are programmed in a FPGA (Field Programmable Gate Array). Radial Doppler velocity averages are then processed to provide reliable measurements from an altitude of nearly $40 \mathrm{~m}$ (to be improved) above ground level and its maximum range corresponding to $720 \mathrm{~m}$. As a matter of fact, 


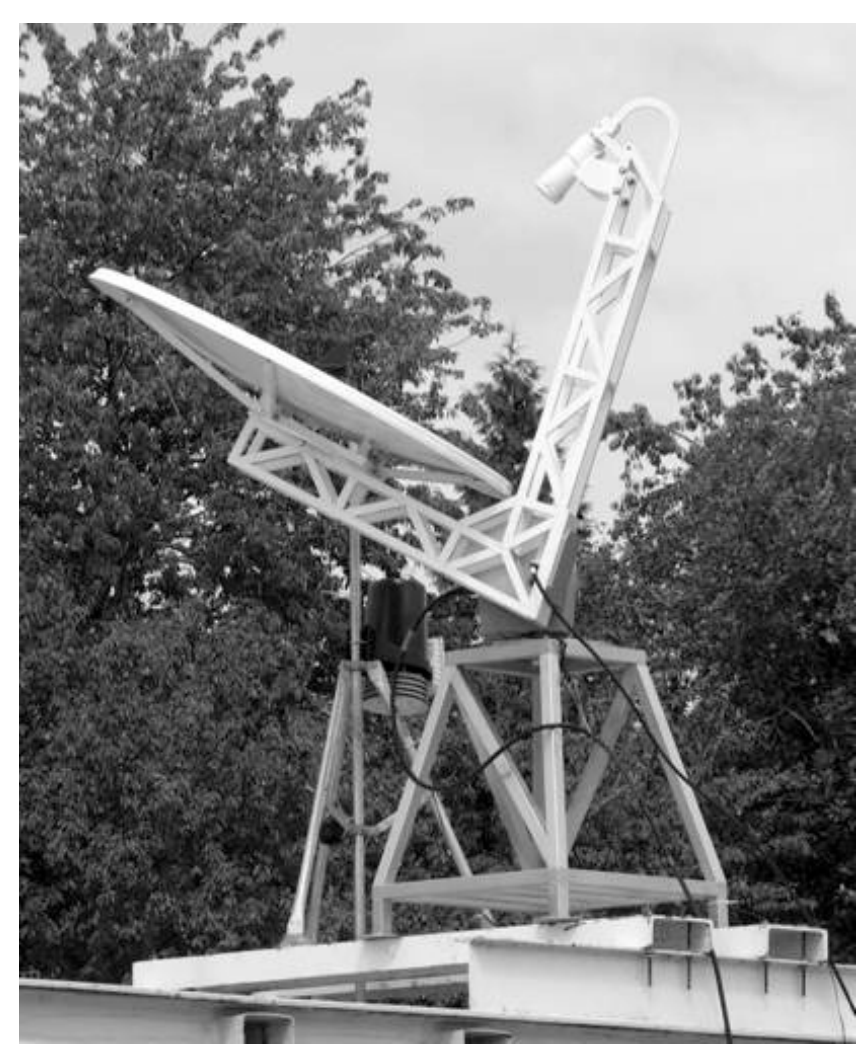

Figure 1: Picture of the CURIE offset antenna at the top a shelter at the SIRTA site (Ecole Polytechnique Palaiseau, France). The antenna is f xed to a positioning system at the left of the picture.

the maximum range can be lower depending on the chosen coded mode.

Here we use the Spano codes, i.e. the technique of pulse compression to improve signal to noise ratio, see SPANO and GHEBREBRHAN (1996).

The Radar processes 4096 FFT points and the number of coherent integrations can vary to respond to signals received from clear air or from precipitation. In clear air, the number generally is in accordance with 300 integrations which correspond to a dwell time between $0.225 \mathrm{~m} \mathrm{~s}$ and $1.485 \mathrm{~m} \mathrm{~s}$, which is considered to be small compared to the coherence time of turbulence, see KELLERER and TOKOVININ (2007). In the ABL, coherence time is in the range between typically $10 \mathrm{~m} \mathrm{~s}$ and $100 \mathrm{~m} \mathrm{~s}$.

During precipitation, i.e., due to the high ref ectivity signal, coherent integrations are not necessary. CURIE data are then analyzed using Matlab where Doppler spectra are averaged and smoothed to discriminate and to eliminate noise errors. The used procedures are the following:

After averaging and smoothing the spectra, we remove the ground clutters (in our case, they are very f ne) and we $\mathrm{ft}$ a Lorentzian function that models the ground clutter (showing the same amplitude and same width at half height).

Then, spectra are modeled and ftted with a Gaussian function from which the spectral power, the Doppler ve- locity and the variances are estimated. The method is applied for clear air or for precipitation.

The number of spectra in an hour depends on the chosen mode, on the repetition period and on the number of coherent integrations. Generally we get one spectrum every 3 seconds.

Due to different kinds of backscatter mechanisms associated with turbulence or with rain drops two types of ref ectivity are used:

- In the presence of turbulence (Bragg scattering):

$$
\eta=0.38 C_{n}^{2} \lambda^{-1 / 3}
$$

where $\eta\left(\mathrm{m}^{-1}\right)$ is radar ref ectivity and $C_{n}^{2}\left(\mathrm{~m}^{-2 / 3}\right)$ is the refractive index structure function.

- In the presence of hydrometeors (Rayleigh scattering); see BATTAN, (1973) :

$$
\eta=\frac{\pi^{5}|K|^{2}}{\lambda^{4}} Z
$$

where $|K|^{2}$ is a function of the complex index of refraction (depending on the electric properties of water) and $Z$ is the radar ref ectivity factor.

Note that mixed cases can also occur when turbulence and precipitation Doppler spectra appear; these can not necessarily be well separated. Other possible mechanisms of scattering for example Mie scattering when scatters are equal or larger than the radar wavelength, are not considered here.

\section{Observations}

\subsection{CURIE observations in clear air}

\subsubsection{Clear air ref ectivity observations}

CURIE Radar is located inside SIRTA (an experimental site located at Ecole Polytechnique, Palaiseau (France) which is dedicated to atmospheric observations with ground based remote sensing techniques (Sodar, Lidar, Radar and radiometers) and local meteorological observations), see http://sirta.ipsl.polytechnique.fr. Measurements were performed mainly during 3 periods in 2007; since July 10, 2008, CURIE works continuously. The f rst period is between March 21 and April 15, 2007, the second period in May ( $\sim 10$ days) and the last period is during September (2 days). Raw primary data were processed and stored, using Labview, in one hour fles. Using the positioning system, CURIE can point automatically along different directions (elevation and azimuth), but as only two days in September were available considering this horizontal wind conf guration, we present only representative results corresponding to a vertically pointing antenna beam conf guration. 

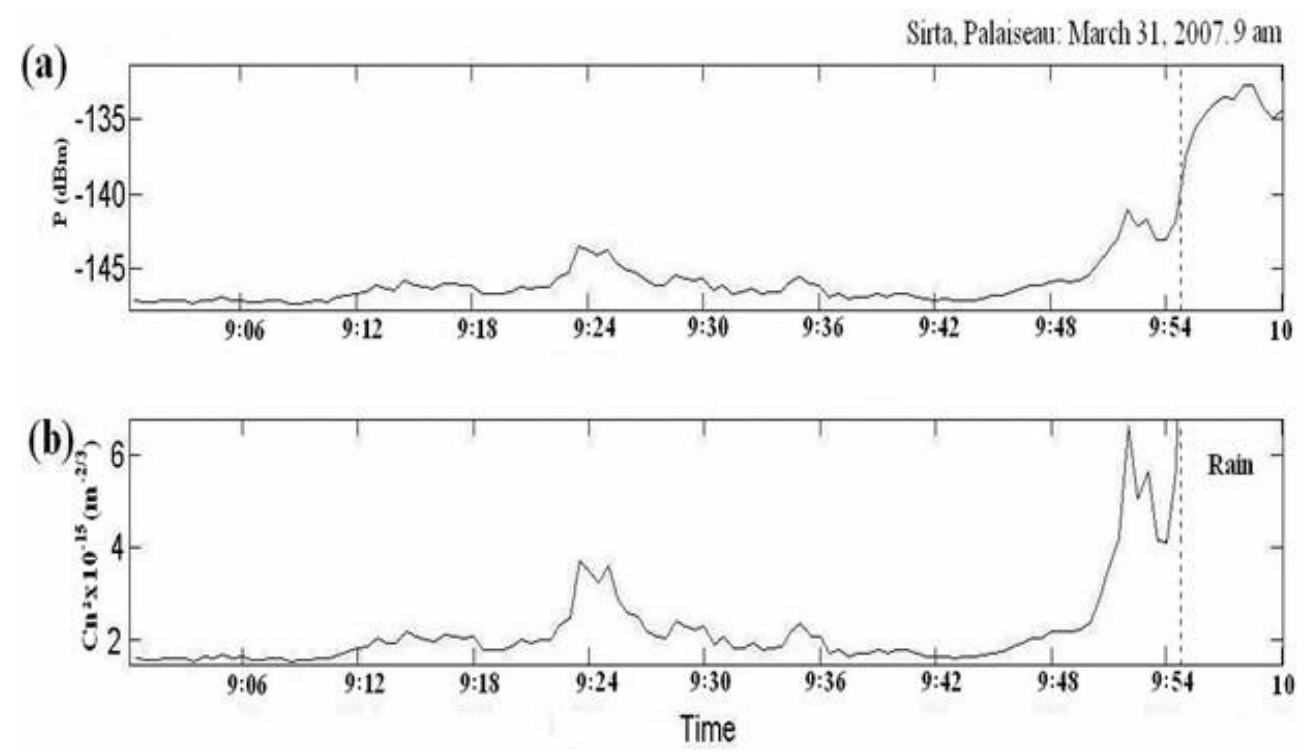

Figure 2: Response of CURIE in clear air at an altitude of $130 \mathrm{~m}$, (a) Received Power $\mathrm{P}$ in $\mathrm{dBm}$ as a function of time, (b) Equivalent $C_{n}^{2}$ (x $10^{-15} \mathrm{~m}^{-2 / 3}$ ) as a function of time; SIRTA on March 31, 2007; local time.

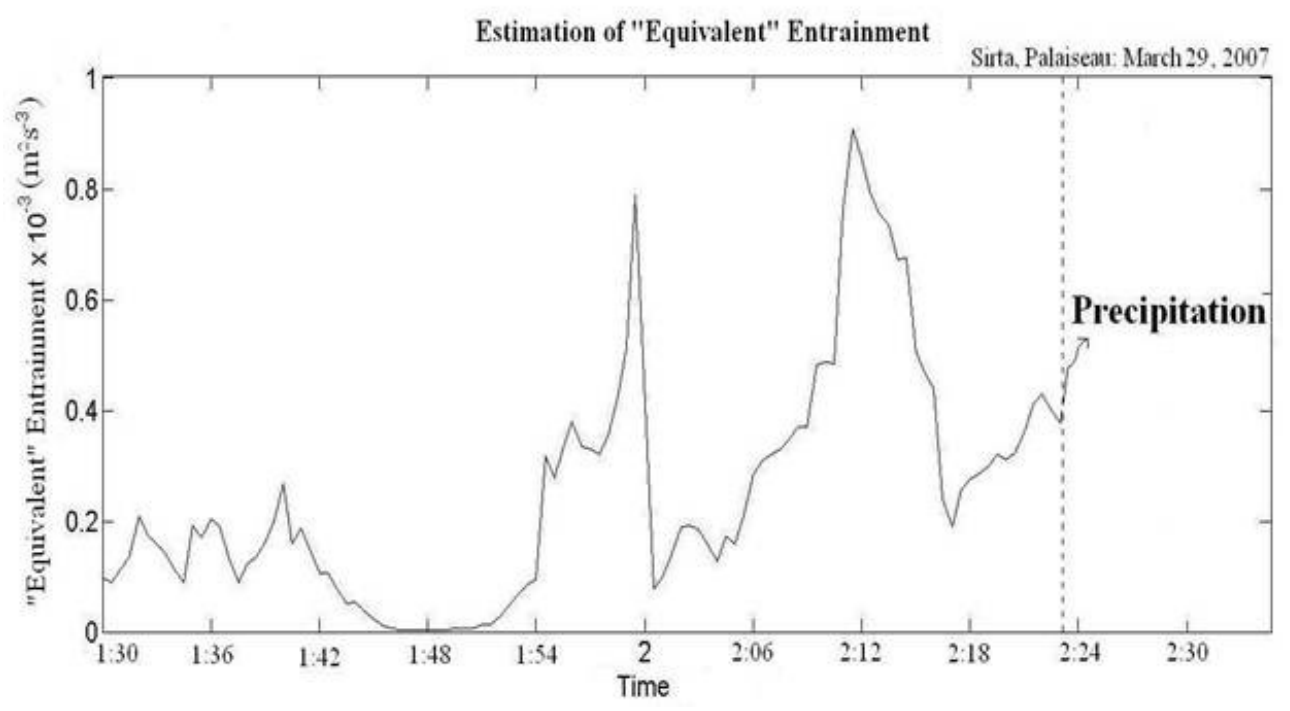

Figure 3: Estimation of the "equivalent" entrainment as a function of time on March 29, 2007 at SIRTA, at the level of the inversion level $\left(\mathrm{m}^{2} \mathrm{~s}^{-3}\right)$; local time.

Different parameters (power spectrum, Doppler velocity, standard deviation of the Doppler velocity, estimations of refractive index structure function) are calculated.

Figure 2 shows the response of CURIE in clear air. Data were collected on March 31, 2007, at 9 am (local time) at an altitude of $130 \mathrm{~m}$. In (a) we plot the power spectrum as a function of time. The signal remains relatively stationary up to the last 10 minutes, where the power increases rapidly due to the initiation of precipitation. In (b), an "apparent" refractive index structure function $C_{n}^{2}$ was computed using equation (2.1). This term of "apparent ref ectivity" is used since CURIE is not calibrated, but CURIE ref ectivity is however known at better than $3 \mathrm{~dB}$, taking into account the radar equation, the antenna beam eff ciency and the radar signal processing algorithm. In the last 10 minutes, due to the different scattering mechanisms, $C_{n}^{2}$ is indeed not estimated. The order of magnitude of the "apparent" $C_{n}^{2}$ is found to be larger than $10^{-16} \mathrm{~m}^{-2 / 3}$ which is the minimum of turbulence measurable by CURIE. Using radiosounding close to the SIRTA, comparisons with $C_{n}^{2}$ were undertaken. A factor two was found between CURIE and the radiosonde data. Though comparisons of $C_{n}^{2}$ from radar and estimations from radiosounding have been published in literature and have shown good agree- 
ment, see as an example RAO et al. (2001), the comparisons cannot be used to calibrate radar but only to give qualitative comparisons. Indeed:

$$
C_{n}^{2}=a^{2} A L_{0}^{4 / 3} M^{2},
$$

TATARSAKII (1971) where $\mathrm{a}^{2}$ is a constant without dimension generally taken as 2.8 but known with an uncertainty of $25 \%$, and:

$$
A=K / K_{m}\left(1-R_{i}\right)
$$

$A$ is a function depending on the eddy diffusion coeff cients for radio index $K$ and momentum $K_{m}$ and $R i$ is the Richardson number. $A$ is supposed to be close to one but is rather uncertain, especially upon the surface layer. An uncertainty of $50 \%$ on $A$ and more can be considered due to other diff culties to compute precisely the Richardson number.

$L_{0}$ is the outer scale of turbulence and can be parameterized as a function of the local mean wind speed, height of observation and stability. Uncertainty on $L_{0}$ can be as large as the spectral peak relative to the outer scale and, corresponding to the initiation of the turbulence cascade, actually is often large, see HANNA (1968).

$M$ depends on temperature, potential temperature, humidity, pressure and respective potential temperature and humidity gradients. An uncertainty larger than $100 \%$ is also possible, particularly due to the computation of the vertical gradients. It is important to remark that parameterizations used to compute the eddy coeff cients are only well established in the surface layer, using Monin-Obukhov similarity, see BUSINGER et al. (1971) and STULL (1988)

It has also to be noted that the presence of bugs which can enhance the ref ectivity, see CAMPISTRON (1975), was not obvious in the early spring and turbulent echoes were observed during clear winter convective situations, when bugs are supposed to be absent or scarce.

\subsubsection{A tentative procedure to determine entrainment $f \mathrm{ux}$ across inversion layers}

It is well known that boundary layer evolution is determined by dynamics of exchange across inversion layers and is related to the entrainment fuxes. BALL (1960) quoted by TENNEKES (1973) suggested that entrainment $f u x$ was related to vertical kinetic energy across the inversion layer, mainly associated with buoyancy effects. This concept was used with Sodar; see DUBOSClARD (1980), FAIRALL (1984) and WEILL and LEHMANN (1990). A rough estimate of entrainment f ux $Q_{i}$ was proposed:

$$
Q_{i}=-A \frac{\sigma_{w}^{3}}{h}
$$

where $A$ was close to 1.4 , see WEILL et al. (1980), (here we use this value) and $h$ is the height of the inversion determined from radar maximum clear air ref ectivity.
The vertical velocity variance across the inversion layer must take into account momentum production across the wind shear transition and buoyancy related to negative heat $f$ uxes at the inversion layer transition. As wind shear has not been estimated, we cannot transform (3.3) into entrainment $\mathrm{f} u x$. Therefore (3.3) cannot be reduced to the virtual sensible heat fux since generally wind shear does not vanish at the inversion layer, and the entrainment which is estimated here is the "equivalent entrainment" which can occur in the absence of wind shear at the inversion level. In case of cloud initiation, it has to be noted that virtual temperature is used due to humid air entrainment across the boundary layer. This mechanism is responsible for cloud formation; see MATHiEU et al. (2004).

Figure 3 shows estimates of the "equivalent" entrainment $f$ uxes from (5), just before precipitation, with data collected on March 29, 2007, local time. Of course, these raw estimations of entrainment $f$ uxes must be validated and compared to cloud parameterization and modeling with different mechanisms as suggested in MATHIEU et al. (2004) as bulk Richardson number. Comparisons with surface fuxes should also to be carried out. In addition, dry and humid buoyancy components due to sensible and latent heat $\mathrm{f}$ uxes, respectively, must be taken into account. Note that Figure 3 represents just a quantity which is supposed to be proportional to entrainment and the constant $A$ has to be determined precisely, performing different experiments during which stable layer height, virtual potential temperature prof les, wind shear, and entrainment $f$ uxes have to be determined. The peak located at around 2 hours is associated with low values of the inversion layer height; this observation is not new and has already been obtained with Sodar, see DUBOSCLARD (1980). This kind of phenomenon occurs often in the presence of gravity waves and oscillations associated with the inversion layers, see EYMARD and WEILL (1979) and WEILL et al. (1987).

\subsubsection{Comparison of vertical velocity $f$ uctuations with UHF radar}

The UHF radar Deg rewind PCL1300 is used by EDF (Electricité De France) to study the wind prof les and is located in SIRTA near CURIE radar. Its peak power is $4 \mathrm{~kW}$, and it broadcasts at a frequency close to 1.238 $\mathrm{GHz},(\lambda=24 \mathrm{~cm})$. The Radar antenna is made out of $f$ ve panels necessary for the formation of the f ve beams (one vertical and four oblique beams). The four oblique antenna beams are tilted $17^{\circ}$ from the vertical. Each panel consists of a network composed of eight antennas. The radar antenna is usually surrounded by a fence designed to reduce ground clutter from $f$ xed objects close by (trees, buildings). It detects the radial Doppler velocity within a volume resolution that has an aperture of $8.5^{\circ}$. It provides reliable measurements from an altitude of about $85 \mathrm{~m}$ above ground level, which has been proved in campaign measurement in Lannemezan 


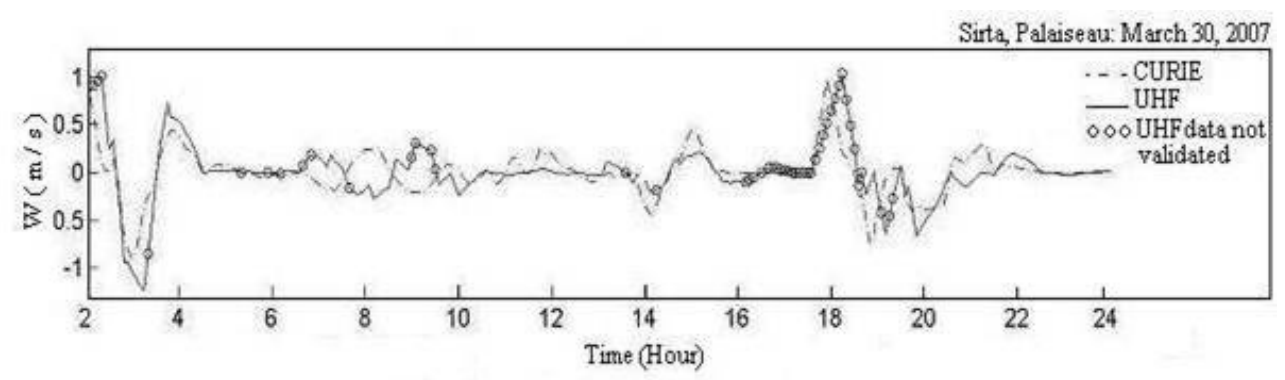

Figure 4: Comparison of vertical velocity fuctuations $\mathrm{W}(\mathrm{m} / \mathrm{s})$ as a function of time on March 30, 2007 at SIRTA, between CURIE and UHF radar; local time.

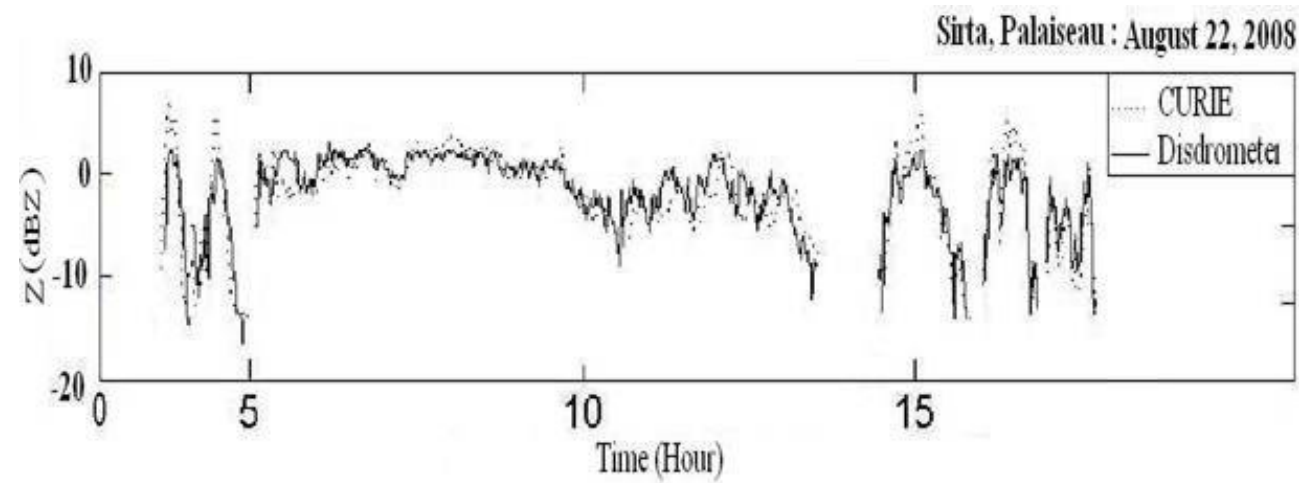

Figure 5: Comparison of ref ectivity (dBZ) between CURIE at $60 \mathrm{~m}$ and the LATMOS disdrometer, as a function of time (local time) during precipitation on August 22, 2008 at SIRTA.

(South West of France), and its maximum range, that depends on the intensity of the echoes from the atmosphere, is about 1500 to $2000 \mathrm{~m}$. Note that the signal received has been reduced using an isolating switch in the receiver.

Data coming from this UHF radar are stored in 5 minute $\mathrm{fles}$, but each $\mathrm{f}$ le from this radar corresponds to moving averages (averages on 30 minutes delayed every 5 minutes).

Figure 4 shows a comparison of vertical velocity between CURIE and the UHF radar, after elimination of a low frequency negative mean tendency associated with each radar and of same order of magnitude. In this Figure, we plot CURIE vertical velocities fuctuations (in dashed line) and UHF radar fuctuations as a function of time (local time) at an altitude of $200 \mathrm{~m}$. These data were collected on March 30, 2007. The black circles correspond to cases where UHF data were not validated. We can observe a good correspondence between these two f uctuations. This relatively good correlation seems to be systematic at least for concomitant observations but mean tendencies have to be analyzed and understood.

\subsection{CURIE measurement during precipitation}

CURIE as an X-band radar with high resolution is very useful to determine precipitation parameters in the lower part of the $\mathrm{ABL}$, especially on sites where rain gauge measurements exist which is a good way to determine the rain estimates precisely. CURIE cannot be compared to high power radars that are used for synoptic meteorology and dynamics of precipitation, however, due to its small maximum range $(720 \mathrm{~m})$ and its resolution $(22.5 \mathrm{~m})$ it is adapted to analyze rain inf uence on the low boundary layer. To calculate the rainfall rate $\mathrm{R}$, the amount of water through a horizontal section of surface unity during a time interval, we use Z-R relationship ( $Z$ is the radar ref ectivity factor). The most widely used Z$\mathrm{R}$ relationship is the Marshall-Palmer relationship, see MARSHALL and PALMER (1948):

$$
Z=200 R^{1.6}
$$

This formula is available for stratiform precipitation which was observed during our experiment, but many other relationships available for stratiform precipitation have been proposed in literature. In case of convective precipitation or mixed cases with alternating stratiform and convective precipitation (with temporary large negative vertical velocities), the application of the MarshallPalmer relationship would lead to erroneous estimations of precipitation rates, see ATLAS et al. (1973).

$Z$ was computed from the relationship between $Z$ and $\eta$, equation (2.2), in the conditions of the approximation of Rayleigh scattering. However, cases can occur during which Rayleigh conditions are not satisf ed, cor- 


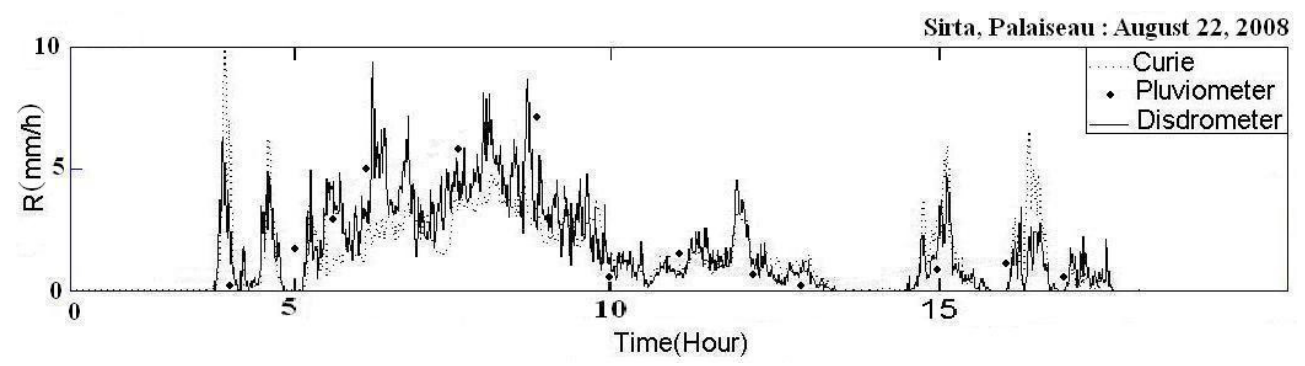

Figure 6: Comparison of Rainfall Rate R $(\mathrm{mm} / \mathrm{h})$ between CURIE at $60 \mathrm{~m}$, the LATMOS disdrometer, and the rain gauge as a function of time (local precipitation) during precipitation at SIRTA on August 22, 2008.

responding to Mie scattering (particle diameters/radar wavelength equal or larger than one) or mixed cases in the presence of turbulence and rain drops when simultaneously Bragg and Rayleigh scattering are suspected to occur and Doppler spectra are diff cult to interpret, see GOSSARD (1988).

We here present only a case of stratiform precipitation which represents what was observed during several months at SIRTA. Accordingly, here it can be supposed that the Rayleigh conditions are fulf lled.

It has to be noted that $Z$ is relative to the volume of the gate scanned by radar. The unit of $Z$ is $\mathrm{mm}^{6} \mathrm{~m}^{-3}$. In our study we use a disdrometer developed in LATMOS, which is an optical instrument (infrared LED used) for measuring all types of precipitation. It enables to record the number, the size and the velocity of raindrops hitting the surface of the disdrometer $\left(100 \mathrm{~cm}^{2}\right)$, allowing for the direct calculation of the ref ectivity, the rainfall rate, the drop size distribution and so on. For more information about the disdrometer see DELAHAYE et al. (2006). $Z$ is related to the number of precipitation drops $N(D)$, e.g. BATTAN (1973), as:

$$
Z=\int_{D_{\min }}^{D_{\max }} N(D) D^{6} d D
$$

$R$ can be computed using:

$$
R=\int_{D_{\min }}^{D_{\max }} N(D) D^{3}[V(D)-w] d D
$$

$D$ is the diameter of the raindrop; $V(D)$ is the velocity of the raindrop; $w$ is the vertical upward component of the wind velocity ( $w=0$ for ground based measurements).

It has to be noted that X-band attenuation inside precipitation events can be large and must be corrected, see WeXler and AtLAS (1963) and ECCLES and MuELLER (1971). In the case of low stratiform precipitation for a path close to $200 \mathrm{~m}$ at $100 \mathrm{~m}$ height, as considered in this study, it is negligible considering a ref ectivity uncertainty smaller than $3 \mathrm{~dB}$. As an example for a rain rate between $1 \mathrm{~mm} / \mathrm{h}$ and $100 \mathrm{~mm} / \mathrm{h}$ and a mean atmospheric temperature of $18^{\circ} \mathrm{C}$ it is found to be between $0.0012 \mathrm{~dB}$ and $0.34 \mathrm{~dB}$.

Figure 5 shows a comparison between CURIE and the LATMOS disdrometer data which were collected on August 22, 2008, at the SIRTA site at Palaiseau. The CURIE antenna was vertically pointing. We plotted the CURIE response in a dotted line and the disdrometer response in a continuous line. We have chosen the third gate $(\sim 60 \mathrm{~m})$ from the radar results, at a height where far $f$ eld conditions begin to be satisf ed. Ref ectivity is calculated in $\mathrm{dBZ}$. The results of the disdrometer and the radar measurements show a very good agreement. The maximum difference is in the order of $3 \mathrm{dBZ}$ which is in the range of radar ref ectivity uncertainty, but can be also explained from the fact that the radar measurement refers to an observed volume, whereas the local measurement refers to a surface.The absence of rain is observed simultaneously from the radar and the surface rain measurement.

In Figure 6, we also show a comparison between CURIE, the LATMOS disdrometer and a classical rain gauge (on the site) in terms of the rainfall rate $R$ at the same date and the same place. Here we use equation (3.4) to compute R from CURIE, and a direct calculation is made from the disdrometer and the rain gauge (rain gauge measurements are relative to one hour). The disdrometer can be considered as a "ground truth" for precipitation measurements and as a means for radar calibration, see WiLLIAMS et al. (2005) and DelahAYE et al. (2006), but the nature of the two signals are different. Before any calibration of CURIE for a measurement of the precipitation rate, we need to use a Z-R relationship corresponding to the type of precipitation as well as to compare separately the evolution of the precipitation event and the measurement results, respectively. We observe an agreement between the results which prove once more that CURIE can be used as an instrument to calculate the parameters of the respective precipitation event. Here the maximum difference between the results of CURIE and the disdrometer is on the order of $3 \mathrm{~mm} / \mathrm{h}$ due to the same reason as with respect to the ref ectivity. 


\section{Conclusion}

CURIE is a prototype which needs improvement, and its validation is ongoing. It appears to be well suited to "urban micrometeorology". Data collected with this small radar during precipitation events were also very encouraging since the precipitation rate in the low boundary layer part as estimated from the vertically pointing CURIE radar corresponds very well to the precipitation rate as measured with a disdrometer. The disdrometer is a useful instrument for precipitation radar calibration; see MCFARQUHAR and LIST (1993). This radar has been designed for low atmospheric boundary layer prof ling. In this paper, we have only presented frst interesting observations in clear air and in precipitation:

- Turbulence observation in the boundary layer, $C_{n}^{2}$ evaluation fuctuations. This observation shows that the sensitivity of CURIE is as expected, but systematic comparisons during different atmospheric conditions with independent estimations remain fundamental to understand if the turbulence response corresponds to inertial turbulence.

Particularly for $C_{n}^{2}$ estimations, comparisons have already been undertaken using radiosounding, but if measured $C_{n}^{2}$ does not generally differ by a factor 2 from CURIE estimates, we cannot consider this a real calibration method. According to literature, the validation of parameterizations with respect to the atmospheric surface layer has to meet higher requirements, since the eddy coeff cients and the external scale of turbulence are not measured but only estimated. Systematic comparisons with other clear air radar systems as done by LOTHON et al. (2002) would give a good indication on the $C_{n}^{2}$ validity and representativeness, but the best method would be the use of systematic comparisons of $C_{n}^{2}$ measurements using airborne measurements or a tethered balloon borne microwave refractometer, see GJESSING et al. (1973). An interesting perspective for calibration and analysis would be using a boundary layer virtual radar simulator as done by SCIPION et al. (2008) using an LES (Large Eddy Simulation). This justif es:

- undertaking a dedicated Boundary Layer f eld experiment to initiate external atmospheric parameters for the model forcing.

- incorporating a typical CURIE radar signal (taking into account of all the radar processes and parameters) in the LES and to compute as an output the boundary layer parameters.

- comparing output parameters as $C_{n}^{2}$ to the CURIE output for validation.
- A preliminary evaluation of a dynamic parameter related to entrainment across a stable layer just before cloud evolution toward precipitation has been undertaken.

More work has to be carried out to determine the consistency of this parameter to infer buoyancy f ux across the inversion layer as done with Sodar by DuBOSCLARD (1980).

This type of analysis is necessary since we have to take into account that CURIE can be applied to clear air physics as well as to precipitation physics in the ABL.

- A comparison of vertical velocity fuctuations with UHF Radar.

It shows good agreement with the measured variables, but going further into scatter mechanisms at different wavelengths is necessary to explain the differences.

- Comparisons of the precipitation rate as obtained with CURIE and with a disdrometer.

The relevant comparisons between precipitation rates justify the use of CURIE for urban hydrology when rain gauges are diff cult to be used due particularly to building effects. CURIE can also document the modif cation of the boundary layer due to precipitation in case of drops evaporation or condensation in the low ABL.

Combining precipitation measurements from the radar and external measurements from disdrometers could also help in the radar calibration, but it requires systematic disdrometer measurements and has to be based on the hypothesis that disdrometer ref ectivity estimates correspond to a ground truth. This is probably not always the case considering differences from radar ref ectivity which gives information on an observed volume whereas disdrometers measure the local precipitation on a surface.

Different works are in progress to validate extensively the instrument:

- Systematic validation of CURIE during different ABL conditions and particularly horizontal wind measurement.

- Precipitation analysis.

- Discrimination of turbulence in the presence of precipitation.

We have only described a few examples for the results as obtained with a vertically pointing antenna, but in the future the orientation capabilities of CURIE will be used for horizontal wind prof ling. For that purpose, real time processing will be improved using fast response relevant operational algorithms since real time data processing is not operational. While CURIE is designed for the application in urban micrometeorology, CURIE has also some potential to be used in the MABL (Marine Boundary Layer). 


\section{List of abbreviations}

ABL: Atmospheric Boundary Layer

CASA: Collaborative Adaptive Sensing of the Atmosphere.

CETP: Centre d'étude des Environnements Terrestre et Planétaires

CURIE: Canopy Urban Research on Interactions and Exchanges

EDF: Electricité De France.

FFT: Fast Fourier Transformer.

FPGA: Field Programmable Gate Array

LATMOS: Laboratoire Atmosphères, Milieux, Observations Spatiales

LES: Large Eddy Simulation

MABL: Marine Boundary Layer

MMR: Micro Rain Radar

SIRTA: Site Instrumental de Recherche par Télédétection Atmosphérique. ST: Stratospheric Troposphere

UBL: Urban Boundary Layer

USA: United States of America

\section{Acknowledgments}

CURIE has received support from INSU (CNRS) (Moyens Mi-Lourds), from SESAME project (funded by Ile de France region), from LATMOS and from IPSL. It is a pleasure to acknowledge all our colleagues who have helped in the development of CURIE and particularly Martial Haeffelin, Scientif c and Technical Head of SIRTA to have given us the opportunity to install CURIE inside SIRTA.

\section{References}

Atlas, D.R., C. SRivastava, R.S. SeKhon, 1973: Doppler radar characteristics of precipitation at vertical incidence. - Rev. Geophys. Space Phys. 11, 1-35.

BALL, F.K., 1960: Control of inversion height by surface heating. - Quart. J. Roy. Meteor. Soc. 86, 483-494.

BATTAN, L.J., 1973: Radar Observation of the Atmosphere. - The University of Chicago Press, Chicago, 324.

Bluestein, H.B., W.P. UNRUH, 1989: Observation of the wind f eld in tornadoes, funnel clouds, and wall clouds with a portable Doppler radar. - Bull. Amer. Meteor. Soc. 70, 1514-1525.

Businger, J.A., J.C. WYNGAARD, Y. IZUMi, E.F. BRADLEY, 1971: fux prof le relationships in the atmospheric surface layer. - J. Atmos. Sci. 28, 181-189.

CAMPISTRON, B., 1975: Characteristic distributions of angel echoes in the lower atmosphere and their meteorological implications. - Bound.-Layer Meteor. 9, 411-426.

Coulter, R.L., T.J. MARTIN, 1986: Results from a high power, high frequency sodar. - Atmos. Res. 20, 157-269.

Delahaye, J.-Y., L. Barthes, P. Gole, J. Lavergnat, J.P. VINSON, 2006: A dual-beam spectropluviometer concept. - J. Hydrol. 328, 110-120.

DUBOSCLARD, G., 1980: A comparison between observed and predicted values for the entrainment coeff cient in the planetary boundary layer. - Bound.-Layer Meteor. 18, 473.
Eccles, P., E.A. Mueller, 1971: X-Band attenuation and liquid water content estimation by a dual-wavelength radar. - J. Appl. Meteor. 10, 1252-1259.

EYMARD, L., A. WEILL, 1979: A study of gravity waves in the planetary boundary layer by acoustic sounding. Bound.-Layer Meteor. 17, 331-345.

FAIRALL, C.W., 1984: Wind shear enhancement of entrainment and refractive index structure parameter at the top of the turbulent mixed layer. - J. Atmos. Sci. 41, 3472-3484.

GIPSON, C.H., 1991: Kolmogorov similarity hypotheses for scalar f elds: sampling intermittent mixing in the ocean and galaxy. - Proceedings of the Royal Society of London 434, 149-164.

Gjessing, D.T., A.G. KuelaAs, E. Golton, 1973: Small scale atmospheric structure deduced from measurements of temperature, humidity and refractive index. - Bound-Layer Meteor. 4, 475-492.

GOSSARD, E.E., 1988: Measuring drop-size distributions in clouds with clear-air-sensing Doppler radar. - J. Atmos. Oceanic Technol. 5, 640-649.

Gossard, E.E., R.B. Chadwick, T.R. Detman, J. GAYNOR, 1984: Capability of surface-based clear air Doppler radar for monitoring meteorological structure of elevated layers. - J. Climate Appl. Meteor. 23, 474-485.

HANNA, S. R., 1968: A Method of Estimating Vertical Eddy Transport in the Planetary Boundary Layer Using Characteristics of the Vertical Velocity Spectrum. - J. Atmos. Sci. 5, 1026-1033.

HILL, R., 1989: Structure functions and spectra of scalar quantities in the inertial-convective and viscous-convective ranges of turbulence. - J. Atmos. Sci. 46, 2245-2251.

Kallistratova, M.A., 1959: Procedure for investigating sound scattering in the atmosphere. - Akad. Zürich 5, 496498.

Kellerer, A., A. Tokovinin, 2007: Atmospheric coherence time in interferometry: def nition and measurement. Astronomic and Astrophysics 461, 775-781.

LitTLE, C.G., 1972: On the detectability of fog, cloud, and snow by acoustic echo sounding methods. - J. Atmos. Sci. 28, 748-755.

LÖFFLER-MANG, M., M. KUNZ, 1999: On the performance of low-cost K-band Doppler radar for quantitative rain measurements. - J. Atmos. Ocean. Technol. 16, 379-386.

Lothon M., B. CAMpistron, S. JaCOBY-KoAly, B. BÉNECH, F. LOHOU, F. GIRARD-ARDHUIN, 2002: Comparison of radar ref ectivity and vertical velocity observed with a scannable C-band Doppler radar and two UHF pro$\mathrm{f}$ lers in the lower troposphere. - J. Atmos. Ocean. Technol. 19, 899-910.

Marshall, J.S., W.M. PALMER, 1948: The distribution of raindrops with size. - J. Meteor. 5, 165-166.

Mathieu, A., A. Lahellec, A. Weill, 2004: Evaluation of a numerical weather forecast model using boundary layer cloud-top temperature retrieved from AVHRR. Mon. Wea. Rev. 132, 915-928.

MCFARQUhAR, G.M., R. List, 1993: The Effect of curve $\mathrm{f}$ ts for the disdrometer calibration on raindrop spectra, Rainfall Rate and radar ref ectivity. - J. Appl. Meteor. 32, 774-782.

MONIN, A.S., 1962: Characteristics of the scattering of sound in a turbulent atmosphere. - Soviet Phys. Acoustics 7 (English Translation), 370.

NefF, W.D., R.L. Coulter, 1986: Acoustic Remote Sensing. - In: LENSCHOW, D.H. (Ed.): Probing the Atmo- 
spheric Boundary Layer, American Meteor. Soc., Boston, MA, 201-266.

Ottersten, H., 1969: Radar Backscattering from the Turbulent Clear Atmosphere. - Radio Sci. 4, 1251-1255.

Peters, G., B. Fisher, T. Andersson, 2002: Rain observation with a vertically looking Micro Rain Radar MMR. Boreal Environ. Res. 7, 353-362.

RaO, D.N., T.N. Rao, M., Venkataratnam, S. ThuLASIRAMAN, S.V.B. RAO, P. SRINIVASUlU, P.B. RAO, 2001: Diurnal and seasonal variability of turbulence parameters observed with Indian mesosphere-stratosheretroposphere radar. - Radio Sci. 36, 1439-1457.

Scipion, D.E., P.B. Chilson, E. Fedorovich, R.P. PALMER, 2008: Evaluation of an LES-based wind prof ler simulator for observations of a daytime atmospheric convective boundary layer. - J. Atmos. Ocean. Technol. 25, 1434-1436.

Spano, E., O. Ghebrebrhan, 1996: Pulse coding techniques for ST/MST radar systems: A general approach based on a matrix formulation. - IEEE Trans. Geosci. Remote Sens. 34, 304-316.

STULL, R.B., 1988: An introduction to boundary layer meteorology, Atmospheric Sciences Library. - Kluwer Academic publishers, $666 \mathrm{pp}$.

TATARSKI, V.I., 1961: Wave propagation in a turbulent medium. - McGRAW-HILL book company, INC.
- 1971: The Effects of the Turbulent Atmosphere on Wave Propagation. - National Technical Information Service, Springf eld, Virginia.

TenneKeS, H.A., 1973: Model for the dynamics of the inversion above a convective boundary layer. - J. Atmos. Sci. 30, 558-565.

Weill, A., H. LehmanN, 1990: Already twenty years of acoustic sounding: some applications. - Z. Meteor. 40, 241-250.

Weill, A., C. Klapisz, F. BAudin, 1986: The CRPE miniSodar: Applications in Micrometeorology and in physics of precipitations. - Atmos. Res. 20, 317-335.

Weill, A., M. Blez, F. LECA, 1987: The observation of gravity waves and horizontal mixing in the atmospheric boundary layer. - Ann. Geophys. 5B, 413-420 .

Weill, A., C. Klapisz, B. Strauss, F. Baudin, C. JauPART, P. VAN GRUNDERBEECK AND J. P. GOUTORBE, 1980: Measuring heat fux and structure function of temperature fuctuations with an acoustic Doppler sodar. - J. Appl. Meteor. 19, 199-205.

WEXLER R., D. ATLAS, 1963: Radar ref ectivity and attenuation of rain. - J. Appl. Meteor. 2, 276-280.

Williams, C.R., K.S. Gage, W. Clark, O. Kucera, 2005: Monitoring the ref ectivity calibration of scanning radar using a prof ling radar and a disdrometer. - J. Atmos. Oceanic Technol. 22, 1004-1018. 